\title{
SATISFAÇÃO E COMPROMETIMENTO ORGANIZACIONAL AFETIVO: UM ESTUDO COM DOCENTES UNIVERSITÁRIOS DO CURSO DE CIÊNCIAS CONTÁBEIS
}

\author{
SATISFACTION AND AFFECTIVE COMMITMENT \\ ORGANIZATIONAL: A STUDY WITH UNIVERSITY \\ TEACHERS OF THE ACCOUNTING S COURSE.
}

Recebido 28-12-2012 Aceito 11-02-2014

\author{
Renata Rouquayrol Assunção ${ }^{1}$ \\ Sylvia Rejane Magalhães Domingos ${ }^{2}$ \\ Augusto Cézar de Aquino Cabral ${ }^{3}$ \\ Sandra Maria dos Santos ${ }^{4}$ \\ Maria Naiula Monteiro Pessoa
}

\section{RESUMO}

As Instituições de Ensino Superior, assim como qualquer outra organização, buscam sobreviver em um mercado cada vez mais competitivo. Nesse cenário, há uma preocupação constante com a otimização da qualidade de vida no trabalho cujo intuito é manter os trabalhadores satisfeitos. Estudos apontam que o funcionário satisfeito no trabalho tende a se comprometer com a organização que o emprega e que esses fatores acabam por influenciar o desempenho do profissional. Em razão disso, tanto a satisfação no trabalho como o comprometimento organizacional se revestem de grande valia, já que essas instituições são responsáveis por promover a transmissão de conhecimento através dos docentes. Assim, o objetivo da presente pesquisa é analisar a relação entre o grau de satisfação e o nível de comprometimento organizacional afetivo dos docentes universitários do curso de Ciências Contábeis. A população é composta pelos professores do curso de Ciências Contábeis das duas instituições cearenses com as maiores notas no Índice Geral de Cursos. Foi possível concluir que a satisfação e o comprometimento organizacional afetivo apresentam níveis moderados de correlação positiva entre si e que as "habilidades e conhecimento relacionado à variável trabalho" como também o "relacionamento com colegas" são fatores determinantes da satisfação dos docentes no trabalho.

Palavras-chave: Satisfação no trabalho; Comprometimento organizacional afetivo; Docentes universitários.

\footnotetext{
${ }^{1}$ Possui graduação em Ciências Contábeis pela Universidade de Fortaleza - UNIFOR. Mestrado em Administração e Controladoria pela Universidade Federal do Ceará - UFC. Atualmente é professora das Faculdades Fanor e Ateneu. Fortaleza, Ceará, Brasil. Email: renatafeaac@gmail.com

2 Possui graduação em Ciências Contábeis pela Universidade Federal do Ceará - UFC. Mestrado em Administração pela Universidade Federal do Ceará - UFC. Fortaleza, Ceará, Brasil. Email: sylvia_rejane@hotmail.com

${ }^{3}$ Possui graduação em Administração pela Universidade de Fortaleza - UNIFOR. Mestrado em Education Administration and Supervision pela University of New Hampshire. Mestrado em Administração pela Universidade Estadual do Ceará - UECE. Doutorado em Administração pela Universidade Federal de Minas Gerais - UFMG. Atualmente é professor associado na Universidade Federal do Ceará - UFC. Fortaleza, Ceará, Brasil. Email: cabral@ufc.br

${ }^{4}$ Possui graduação em Ciências Econômicas e mestrado em Economia pela Universidade Federal do Ceará - UFC. Doutorando em Economia pela Universidade Federal de Pernambuco - UFPE. Atualmente é professora na Universidade Federal do Ceará - UFC. Fortaleza, Ceará, Brasil. Email: smsantos@ufc.br

5 Possui graduação em Ciências Econômicas pela Universidade Federal de Santa Maria - UFSM. Mestrado em Economia pela Universidade Federal do Ceará- UFC. Doutorando em Engenharia de Produção pela Universidade Federal de Santa Catarina - UFSC. Atualmente é professora associada na Universidade Federal do Ceará - UFC. Fortaleza, Ceará, Brasil. Email: naiula@ufc.br
} 


\section{ABSTRACT}

The higher education establishments, as well as any other organization, seek to survive in an increasingly competitive market. In this scenario, there is a constant concern for improving the quality of life within the work environment whose aim is to keep workers satisfied. Studies show that the degree of worker's satisfaction at work is directly related to how committed to the organization he is and also these factors could influence the performance of the worker. Therefore both the worker's satisfaction and the organization commitment are of great importance since these higher education establishments are responsible for promoting the exchange of knowledge through teaching. The objective of the present research is to analyze the relationship between degree of satisfaction and affective commitment organizational of university teachers of the Accounting's course. The group used on this research was made of by accounting professors of two higher education establishments that hold the highest evaluation grades in Ceará. It was concluded that the satisfaction and the affective commitment have moderate levels of positive correlation between them. In addition, the skills and knowledge related to the work as well as peer relationship are determinant factors of their level of satisfaction within work.

Keywords: Satisfaction at work. Affective commitment organizational. University teachers.

\section{INTRODUÇÃO}

O crescente número de Instituições de Ensino Superior (IES) no Brasil torna o mercado de educação superior cada vez mais competitivo. Dessa forma, as organizações precisam estar atentas às mudanças e ao atendimento das necessidades do público alvo desse mercado. Não diferente do cenário empresarial, as IES devem buscar elementos que possam proporcionar vantagem competitiva. Rios (2009) destaca como estratégia competitiva o investimento em capital humano, que intensifica os estudos a respeito do comportamento organizacional, bem como, sobre satisfação no trabalho, o comprometimento organizacional e outros indicadores.

Nesse contexto, Reges (2012) afirma que as organizações são constituídas de pessoas e que dependem delas para alcançar seus objetivos. Além disso, empresas bem sucedidas buscam valorizar os recursos humanos, que constituem seu principal patrimônio, através da conscientização da necessidade de investir na qualidade de vida no trabalho, cujo objetivo é manter seus funcionários saudáveis e motivados (SIQUEIRA; KURCGANT, 2012).

Todavia, a motivação no trabalho começou a estar associada a vários outros conceitos, mas em especial aos de satisfação, comprometimento e envolvimento (AMBROSE; KULIK, 1999). Apesar disso, esses conceitos se diferem, pois a satisfação no trabalho está relacionada ao nível de contentamento; o comprometimento organizacional se refere aos afetos dirigidos à organização; e o envolvimento no trabalho, ao nível de identificação e de afinidade com o trabalho realizado (GONDIM; SILVA, 2004).

De forma que, enquanto a satisfação no trabalho está relacionada ao sentimento em relação ao trabalho, o comprometimento está relacionado à responsabilidade, ou seja, comprometer-se significa assumir responsabilidade sobre algo (MENEGON; CASADO, 2006). Para Souza Filho (2008), o comprometimento organizacional abrange pontos em torno do relacionamento existente entre o colaborador interno, que, normalmente, almeja satisfação no trabalho, e a empresa, que, por sua parte, aguarda maior compromisso deste colaborador. Para Cruz et al. (2012), o comprometimento organizacional vem sendo crescentemente pesquisado no contexto contemporâneo, em que a lógica taylorista de organização e gestão do trabalho, bem como o modelo burocrático e a noção de emprego permanente têm sido postos em xeque.

Siqueira e Gomide Jr. (2004) reportam que pessoas satisfeitas no trabalho são aquelas que menos planejam sair da empresa onde trabalham, que menos têm faltas, que possuem melhor desempenho e maior produtividade. Afirmam ainda que o indivíduo satisfeito no trabalho tende 
a manter em níveis altos o seu envolvimento com o trabalho que realiza e a se comprometer com a organização que o emprega. Assim, eles concluem que a satisfação e o comprometimento são vínculos que tendem a apresentar níveis significativos de correlação positiva entre si.

Na pesquisa desenvolvida por Bouzada, Kilimnik e Oliveira (2012), muitos dos docentes universitários entrevistados consideram ser fator preponderante, para o exercício da docência, o gostar de dar aulas. Logo, é possível crer que o comprometimento dos docentes com as instituições ocorre pela existência de uma ligação emocional que se traduz pela vontade de estar lá, não por serem obrigados ou por necessidade, mas por quererem. Esse fato vincula o comprometimento do docente especificamente ao comprometimento organizacional afetivo (ALLEN; MEYER, 1990).

Rowe (2008), em seu estudo com docentes do ensino superior, concluiu que as relações com o trabalho influenciam significativamente seus desempenhos. A autora ressaltou ainda nos resultados da pesquisa a importância do comprometimento com a organização para o alcance de um desempenho superior do trabalhador.

A partir desse conhecimento, surge a seguinte questão de pesquisa: Qual a relação entre o grau de satisfação e o nível de comprometimento afetivo no trabalho dos docentes universitários do curso de Ciências Contábeis?

Constitui objetivo geral da pesquisa, analisar a relação entre o grau de satisfação e o nível de comprometimento afetivo no trabalho dos docentes universitários do curso de Ciências Contábeis de duas universidades cearenses. Adicionalmente, têm-se os seguintes objetivos específicos: (1) comparar o grau de satisfação e o nível de comprometimento afetivo no trabalho dos docentes das universidades escolhidas; e (2) identificar os fatores determinantes da satisfação no trabalho dos docentes.

Os docentes do ensino superior podem ser considerados fundamentais para a sociedade contemporânea, pois atuam junto com a geração e a disseminação do conhecimento impulsionando o desenvolvimento do país. Assim, ressalta-se o importante papel dos professores universitários, que são profissionais educadores e formadores do capital humano. Nesse sentido, a relevância desse trabalho deve-se ao fato de analisar a satisfação no trabalho e o comprometimento afetivo dos docentes universitários do curso de Ciências Contábeis haja vista que esses fatores influenciam no desempenho desses profissionais e, sobretudo, para dar conhecimento às instituições dos resultados da pesquisa que de alguma forma contribui para a melhoria da gestão de seus recursos humanos. De forma que, a hipótese deste trabalho é verificar se há uma correlação positiva quanto à satisfação e o comprometimento afetivo no trabalho dos docentes do curso de Ciências Contábeis.

Visto que a contabilidade está evoluindo academicamente e o número de pesquisas nessa área cresceu muito nos últimos cinquenta anos. Além de se consolidar e expandir, o campo das Ciências Contábeis em relação à pesquisa está estabelecido e é influenciado por teorias econômicas, sociológicas e psicológicas (FARIAS, 2012). Em virtude das alterações que ocorreram nos últimos anos, tal como a internacionalização das normas brasileiras de contabilidade, há uma expectativa grande quanto à mudança cultural, compreendida como a filosofia de privilegiar a essência sobre a forma (GERON, 2008). Além disso, Peleias et al. (2007), através da pesquisa sobre o ensino da contabilidade no Brasil, verificaram que do mesmo modo que essa ciência evoluiu, o curso de Ciências Contábeis passou por diversas mudanças, estando inclusive associado ao progresso da sociedade. Portanto, a escolha do curso de Ciências Contábeis para essa pesquisa se dá por essas razões.

Quanto aos objetivos, a pesquisa é descritiva e quanto à abordagem é quali-quantitativa, tendo sido realizada mediante um survey. A coleta de dados foi feita através de um questionário com três blocos de perguntas que abordaram os seguintes temas: caracterização dos entrevistados, satisfação no trabalho e comprometimento organizacional afetivo. Foram entrevistados 42 professores de duas universidades cearenses, num total de 64 . 
O estudo estrutura-se da seguinte forma: introdução, que consiste no presente segmento e apresenta o tema, os objetivos e a justificativa; referencial teórico, onde são tratados os temas relativos à satisfação e ao comprometimento; metodologia, onde se trata dos aspectos metodológicos do presente estudo; análise dos resultados, onde são apresentados, analisados e comparados os resultados da pesquisa empírica; considerações finais; e referências.

\section{REFERECIAL TEÓRICO}

\subsection{A Teoria dos Dois Fatores de Frederick Herzberg}

A satisfação dos funcionários das organizações modernas é considerada um elemento de competitividade, defendida inclusive como diferencial estratégico. Locke (1976) definiu satisfação como um estado emocional agradável resultante de um trabalho ou experiências de trabalho. Para Schermerhorn Jr., Hunt e Osborn (1999, p. 93), a satisfação no trabalho pode ser concebida como "o grau segundo o qual os indivíduos se sentem de modo positivo ou negativo com relação ao seu trabalho. É uma resposta emocional às tarefas de trabalho assim como às condições físicas e sociais do local de trabalho."

Com o passar do tempo, a satisfação dos funcionários no trabalho se tornou relevante para as organizações, sejam elas públicas ou privadas, de forma que descobrir o que proporciona satisfação no trabalho tem sido alvo de vários estudos e pesquisas (REGES, 2012). Martinez e Paraguay (2003, p. 59) afirmam que "a satisfação no trabalho é um fenômeno amplamente estudado e esse interesse decorre da influência que a mesma pode exercer sobre o trabalhador."

Durante os anos de 1950 e 1960, Frederick Herzberg conduziu por vários anos uma pesquisa sobre motivação no trabalho e seus efeitos na satisfação e na saúde mental dos empregados. Procurou investigar até que ponto as formas das organizações mostravam-se apropriadas para satisfazer as necessidades das pessoas e proporciona-Ihes felicidade. Assim, Herzberg e alguns colegas conduziram a pesquisa com 200 pessoas que trabalhavam em uma indústria de Pittsburgh. Foi questionado ao grupo respondente sobre situações em que eles haviam se sentido especialmente felizes em relação ao trabalho. O mesmo foi feito para situações extremamente desagradáveis vividas pelos entrevistados. O objetivo era descobrir possíveis razões que haviam levado a tais momentos. As respostas foram classificadas buscando determinar os tipos de eventos no trabalho que levavam a situações de satisfação e insatisfação (PUGH; HICKSON, 2004).

Cinco fatores destacaram-se como determinantes da satisfação no trabalho: realização, reconhecimento, atratividade do trabalho em si, responsabilidade e progresso. A análise das situações de insatisfação mostrou que seus determinantes eram de natureza diversa e eram concernentes à política e administração da empresa, supervisão, salário, relações interpessoais e condições de trabalho. Herzberg concluiu que satisfação e insatisfação no trabalho não são o oposto um do outro, ou seja, o contrário de satisfação não é insatisfação, mas a não satisfação. Logo, a teoria dos dois fatores, como ficou conhecida, sugere que os fatores envolvidos na geração de satisfação no trabalho são independentes e distintos dos fatores que levam à insatisfação no trabalho, pois se associam a dois diferentes conjuntos de necessidades humanas (HERZBERG, 1999).

Nesse contexto, os fatores relacionados à satisfação são aqueles relacionados às necessidades das pessoas de realizarem seus potenciais humanos de perfeição denominados fatores motivacionais. Já os fatores relacionados à insatisfação são aqueles associados às necessidades primordiais do ser humano denominados fatores higiênicos (PUGH; HICKSON, 2004). Para Herzberg (2003), os fatores higiênicos referem-se às condições que cercam o empregado, enquanto ele trabalha, englobam condições físicas e ambientais do trabalho, o salário, os benefícios sociais, as políticas da empresa, 
entre outros, ou seja, compõem os fatores tradicionais empregados pelas organizações para alcançar motivação dos funcionários. Já os fatores motivacionais fazem referência ao conteúdo do cargo, aos trabalhos e aos deveres pertinentes do cargo em si. Para o autor, os fatores motivacionais estão sob o controle do indivíduo, pois estão relacionados com aquilo que faz e desempenha.

De acordo com Martins e Santos (2006), a teoria dos dois fatores de Herzberg é provavelmente a primeira teoria que explica a satisfação com o trabalho. Além disso, reforçam que a maior contribuição desses estudos foi identificar a importância do crescimento psicológico como condição necessária para satisfação no trabalho e demonstrar que este crescimento vem do próprio trabalho. Independentemente da concepção adotada de satisfação no trabalho, não há como negar que este aspecto interfere no ambiente de trabalho e na vida pessoal dos trabalhadores.

\subsection{O Comportamento Organizacional Afetivo de Allen e Meyer}

O maior valor patrimonial que uma empresa pode ter é representado por seus ativos intangíveis como, por exemplo: marca, tecnologia e atendimento diferenciado. No contexto organizacional do século XXI, onde se valoriza o capital humano e almeja-se ter funcionários que façam a diferença para os resultados da empresa, o comportamento humano destaca-se como um fator importante (COSTA, 2011). Assim, a busca das empresas por colaboradores que assumam o seu trabalho como um desafio, que lutem para que as empresas tenham altos níveis de desempenho e que se comprometam com os objetivos da instituição é constante, visto que uma das premissas comuns aos estudos do comprometimento com o trabalho é de que níveis elevados de comprometimento contribuem para níveis elevados de desempenho empresarial (MEDEIROS, 2003).

Ribeiro e Bastos (2010) compreendem que o comprometimento dos funcionários de uma organização é uma das forças relevantes que compõe a vitalidade competitiva da organização. Em determinadas áreas, as vantagens competitivas estão cada vez mais efêmeras em consequência da capacidade dos concorrentes de minimizar com mais eficácia esse diferencial. Apesar disso, ainda há aspectos que são únicos e exclusivos das organizações, ou seja, que não podem ser copiados, dentre eles pode-se destacar o comprometimento dos funcionários de uma organização (RIBEIRO; BASTOS, 2010). Borges e Medeiros (2007b) associam esse comprometimento à identificação, ao apego e ao compromisso. Ressaltam ainda que o mesmo vai além do sentimento de lealdade passiva do indivíduo com a organização, pois também envolve uma relação ativa em prol do bem-estar da organização.

Partindo dessa compreensão, percebe-se que as organizações almejam ter funcionários comprometidos com seu trabalho assim como com seus valores, crenças, estratégia e resultados. De acordo com Costa e Bastos (2009) o comprometimento com o trabalho é considerado um importante conceito para compreensão de como se articula o vínculo das pessoas com os seus trabalhos e empresas empregadoras. No decorrer da última década, com o propósito de elucidar as bases desse vínculo foram desenvolvidos diversos estudos e a esse vínculo foi conferido o nome de comprometimento organizacional (SIQUEIRA; GOMIDE JR., 2004).

Para Gouldner (1960) o comprometimento não é um construto unidimensional, ou seja, limitado, já que há "dimensões diferentes no comportamento e no vínculo dos indivíduos com as organizações" (BORGES; MEDEIROS, 2007a, p. 62). Então, a partir do entendimento de que os enfoques unidimensionais eram componentes presentes no comprometimento organizacional, os modelos multidimensionais do comprometimento organizacional começaram a ser considerados (MEDEIROS et al, 2005).

Segundo Cruz et al. (2012), Allen e Meyer (1990) são apontados, por alguns autores, como os pesquisadores mais relevantes dos anos noventa no campo do comprometimento organizacional. Destacam ainda que o modelo tridimensional ou de conceitualização de três componentes do comprometimento desenvolvido por esses professores canadenses é o modelo de 
maior aprovação entre os estudiosos. A medida de comprometimento que operacionaliza o modelo proposto por esses autores surgiu como uma alternativa às medidas anteriores, na busca de maiores validade e confiabilidade (ROWE; BASTOS; PINHO, 2011).

Allen e Meyer (1990) definem o comprometimento organizacional em três componentes: afetivo, instrumental e normativo. $\mathrm{O}$ afetivo (affective commitment) é o comprometimento como um envolvimento, como uma afeição, onde acontece identificação com a empresa, onde funcionários com um elevado comprometimento afetivo continuam na empresa porque desejam; o instrumental (continuance commitment) é compreendido como custos vinculados à saída da empresa, onde trabalhadores com forte comprometimento instrumental continuam na organização porque necessitam; e, por fim, o normativo (normative commitment) entendido como um dever em continuar na empresa, onde trabalhadores com forte comprometimento normativo permanecem porque sentem que são obrigados.

Siqueira e Gomide Jr. (2004) entendem que esse modelo reconhece o comprometimento organizacional como uma combinação de três componentes: o desejo (comprometimento afetivo), a necessidade (comprometimento instrumental) e a obrigação moral (comprometimento normativo). Assim, apesar da ampla aceitação do modelo, a sua multidimensionalidade vem sendo criticada em razão do antagonismo e da controvérsia que há entre essas dimensões, pois compreende-se que "por evoluírem de diferentes causas, acabam por resultar, dessa forma, em diferentes consequências" (MAIA; BASTOS, 2011, p. 393).

Com o intuito de avaliar as relações entre comprometimento afetivo, instrumental e normativo nas organizações; e as relações entre as três formas de comprometimento e as variáveis identificadas como seus antecedentes, correlatos e consequentes do modelo tridimensional, Meyer et al. (2002) realizaram meta-análises. Descobriram que as três formas de comprometimento estão relacionadas de maneira distinguível uma da outra, bem como da satisfação no trabalho, envolvimento com o trabalho e comprometimento profissional.

As variáveis antecedentes, correlatos e consequentes são indispensáveis para a compreensão do comprometimento organizacional, pois permite a interpretação do fenômeno de forma sistêmica. Podem ser compreendidas respectivamente como: "variáveis com potencial de gerar comprometimento"; "variáveis normalmente associadas ao comprometimento"; e "variáveis resultantes do comprometimento" (PINTO, 2011, p. 34). A Figura 1 apresenta as relações entre o comprometimento e essas variáveis.

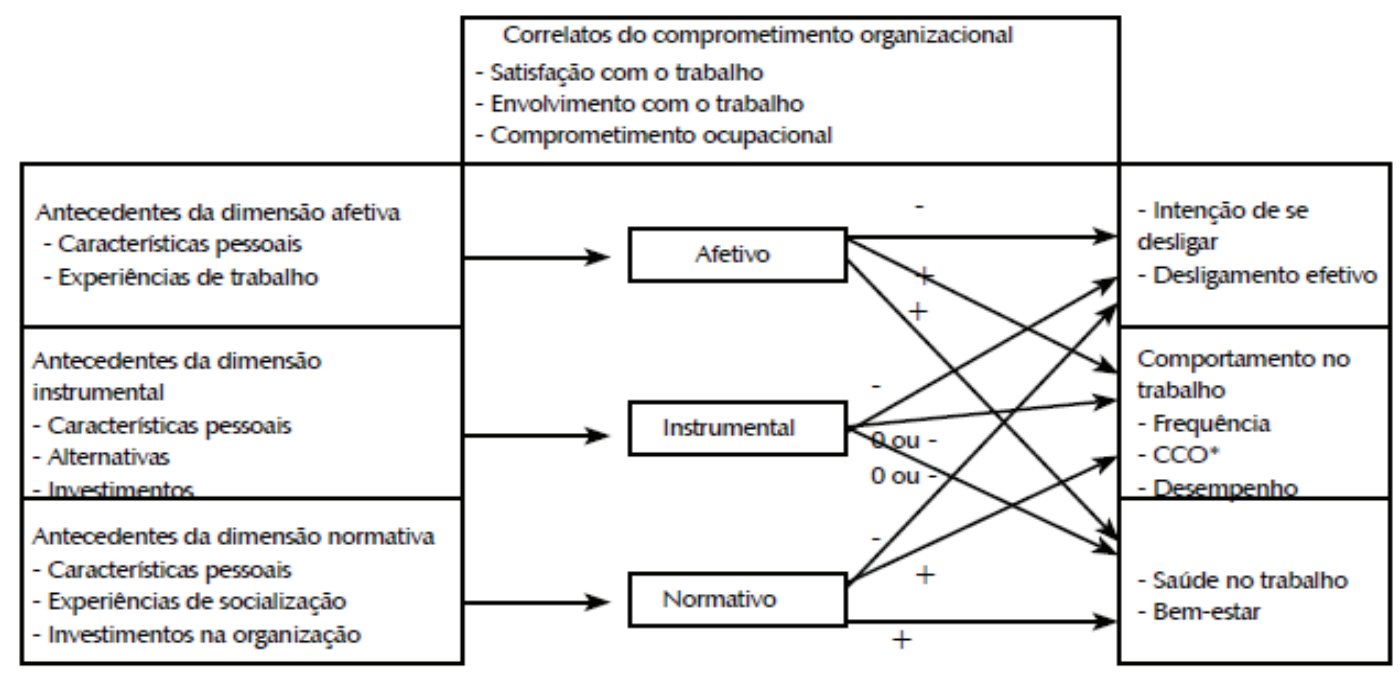

Figura 1 - O modelo tridimensional de Allen e Meyer e seus antecedentes, correlatos e consequentes.

Fonte: Traduzido e adaptado de Meyer et al. (2002).

*Comportamento de cidadania organizacional 
É possível observar, a partir da Figura 1, que os antecedentes da dimensão afetiva, ou seja, das variáveis que podem potencializar o comprometimento organizacional, abrangem as características pessoais e experiências de trabalho. Em relação à consequente afetiva, que é relacionada ao resultado do comprometimento organizacional, há três possíveis resultados: intenção de se desligar; comportamento no trabalho; e saúde no trabalho e bem-estar. De forma que apenas o primeiro resultado, é negativo, em virtude do funcionário querer se desligar da empresa; e os demais, positivos, pois trazem benefícios diretos ao empregado (MEYER et al, 2002).

A pesquisa de Costa e Bastos (2009), que analisou a relação entre o indivíduo, o trabaIho e a organização, em 32 organizações agrícolas, verificou que quanto maior é a satisfação com o trabalho, maior é o comprometimento com o trabalho, com a organização e afetivamente. $\mathrm{Na}$ investigação realizada com profissionais da saúde, Vargas, Birrer e Minello (2012) verificaram que o comprometimento afetivo se destacou dos demais. Os autores consideram que isso pode indicar a vivência de experiências positivas relacionadas a um apego emocional. Maciel e Camargo (2011, p. 449) concluíram em seus estudos que "a satisfação no trabalho figura como significativo antecedente atitudinal do comprometimento" e, sob os aspectos do comprometimento afetivo, entendem que "a satisfação reflete a reafirmação da ligação emocional do indivíduo com a organização". Assim, o comprometimento afetivo se mostra na intenção do funcionário de se esforçar pela organização (MOWDAY; STEERS; PORTER, 1979).

\section{METODOLOGIA}

Dado os objetivos propostos, realizou-se um estudo descritivo, o qual consiste em avaliar e relatar as características de um determinado problema ou questão, estabelecendo-se relações entre as variáveis em foco. Quanto à abordagem da pesquisa, se utilizou de métodos qualitativo e quantitativo, pois foram examinadas as variáveis do estudo para obter um entendimento sobre satisfação e comprometimento; e se utilizou de testes estatísticos para descrever essas variáveis (COLLIS; HUSSEY, 2005).

A pesquisa caracteriza-se como survey, visto que esse método de pesquisa envolve a coleta e a quantificação de dados sobre características e opiniões, que permite confirmar uma determinada teoria de comportamento social. Além disso, optou-se por esse método visto o interesse de estudar a relação entre a satisfação e o comprometimento afetivo em uma determinada amostra. Como pode ser utilizado para determinar relações entre variáveis no período da pesquisa, é compreendido como survey interseccional (BABBIE, 2005).

No que se refere aos meios, a pesquisa é bibliográfica, pois foi realizado um levantamento de material editado, tais como periódicos, trabalhos monográficos, anais de evento e livros (MARTINS; THEÓPHILO, 2007). Pode ser considerado ainda como um estudo correlacional, visto que se pretendeu avaliar a relação entre os conceitos e as variáveis de satisfação e comprometimento no trabalho, os quais foram apresentados no referencial teórico deste trabalho (SAMPIERI; COLLADO; LÚCIO, 2006). Os dados são primários, pois foram coletados diretamente na fonte (MARTINS; THEÓPHILO, 2007).

A coleta dos dados foi feita através de um questionário, com o objetivo de descobrir como os professores se sentem em relação à satisfação e ao comprometimento no trabalho. Logo, para viabilizar essa mensuração foi utilizada a escala de Likert de 5 pontos, permitindo associar cada resposta à um valor numérico. Assim, os dados qualitativos transformados para representar uma série quantitativa foram analisados por meio do somatório de pontos atribuídos a cada questão (MARTINS; THEÓPHILO, 2007). 
Para a escolha da população deste estudo, foi considerado o Índice Geral de Cursos (IGC), que é uma medida utilizada pelo Instituto Nacional de Estudos e Pesquisas Educacionais (Inep), do Ministério da Educação, para avaliar as instituições de educação superior, públicas e privadas. Dessa forma, com base nas notas divulgadas na tabela do IGC do ano de 2010, as duas universidades cearenses escolhidas a partir das maiores notas foram: Universidade Federal do Ceará (UFC) e a Universidade de Fortaleza (UNIFOR). Assim, a população é composta de 64 docentes universitários do curso de Ciências Contábeis da UFC e da UNIFOR.

No dia 8 de junho de 2012, foi enviado aos docentes um e-mail com o intuito de informá -los sobre a realização da pesquisa, o seu propósito e a sua finalidade. 0 instrumento de coleta de dados utilizado foi um questionário aplicado presencialmente durante o período de 11/06/2012 a $15 / 06 / 2012$. Nesse mesmo período, alguns docentes optaram por respondê-lo via e-mail. A amostra totalizou 42 docentes, ou seja, $65 \%$ da população.

O questionário foi estruturado com três blocos. O primeiro bloco apresenta quatro questões que se relacionam com os dados que caracterizam a amostra do estudo, tais como nível de escolaridade, carga horária de trabalho, tempo de serviço na empresa e gênero.

O segundo bloco, que teve como propósito analisar o grau de satisfação dos docentes com base na teoria dos dois fatores de Herzberg, foi estruturado a partir do questionário utilizado no estudo desenvolvido por Silva Júnior (2001) no qual foram relacionadas cinco questões relativas às seguintes variáveis: trabalho (carga horária; reconhecimento; trabalho interessante; trabalho/conhecimentos e habilidades; tarefa x função), relacionamento (relacionamento com colegas; relacionamento com superiores; interesse da universidade em relacionamento; investimento da universidade em relacionamento), salário (compatível com atividades; comparação com outras universidades; condizente com a situação financeira da universidade), perspectiva (desenvolvimento profissional; desenvolvimento pessoal; promoção; desempenho; apoio ao estudo) e autonomia (liberdade de decisão; responsabilidade $x$ autonomia; supervisão). Cada uma das questões deste bloco foi analisada com a utilização de uma escala do tipo Likert, de cinco pontos, na qual: 1 significa muito insatisfeito; 2- insatisfeito; 3 indiferente; 4- satisfeito e 5- muito satisfeito. O Quadro 1 apresenta um modelo de questão utilizada para medir o grau de satisfação dos docentes universitários.

\begin{tabular}{|c|c|l|l|l|l|}
\hline $\begin{array}{c}\text { 5. Variável } \\
\text { AUTONOMIA }\end{array}$ & $\begin{array}{c}\text { Muito } \\
\text { insatisfeito }\end{array}$ & Insatisfeito & Indiferente & Satisfeito & $\begin{array}{c}\text { Muito } \\
\text { satisfeito }\end{array}$ \\
\hline $\begin{array}{c}5.1 \text { Liberdade de } \\
\text { Decisão }\end{array}$ & & & & & \\
\hline $\begin{array}{c}5.2 \text { Responsabilidade } \\
\text { x Autonomia }\end{array}$ & & & & & \\
\hline 5.3 Supervisão & & & & & \\
\hline
\end{tabular}

Quadro 1 - Instrumento de Coleta

Fonte: Adaptado de Silva Júnior (2001).

O terceiro e último bloco objetivou medir o nível de comprometimento organizacional afetivo dos docentes com as Universidades, em que eles trabalham, através de 18 questões relacionadas à temática e de acordo com o modelo de Allen e Meyer (1990). Também foi utilizada uma escala de Likert, de cinco pontos, na qual: 1- significa nada; 2- pouco; 3- mais ou menos; 4- muito e 5- extremamente. Logo para avaliar os sentimentos positivos e negativos com a organização, ou seja, atribuir um nível de comprometimento afetivo, os valores dos itens negativos (desgostoso com ela, distante dela e desiludido com ela) foram invertidos antes de se calcular 
os pontos. Assim, se o docente marcou 1 no item negativo será invertido para $5 ; 2$ para $4 ; 3$ será mantido 3; 4 para 2 e 5 para 1 (BASTOS et al, 2008). O objetivo de usar a escala de Likert foi verificar a intensidade de ocorrência de cada questão. O Quadro 2 apresenta um modelo de item utilizado para avaliar o nível de comprometimento afetivo dos docentes universitários.

\begin{tabular}{|c|c|c|c|c|c|}
\hline $\begin{array}{c}\text { A universidade onde } \\
\text { trabalho faz-me sentir... }\end{array}$ & Nada & Pouco & $\begin{array}{c}\text { Mais ou me- } \\
\text { nos }\end{array}$ & Muito & $\begin{array}{c}\text { Extrema- } \\
\text { mente }\end{array}$ \\
\hline 01. Confiante nela & & & & & \\
\hline
\end{tabular}

Quadro 2 - Instrumento de Coleta

Fonte: Adaptado de Meyer e Allen (1991).

Os itens respondidos com mais de uma resposta ou com nenhuma, não tiveram nenhuma pontuação atribuída. Para validar o questionário, foi realizado um pré-teste, com um grupo de 03 professores de cada uma das Universidades, mas de curso diferentes, ou seja, atuam nas mesmas funções e, portanto, estariam aptos a responder.

Os dados foram tabulados em uma planilha do software Microsoft Excel e, posteriormente, para proceder com a análise foi utilizado o - Statistical Package for the Social Sciences (SPSS ${ }^{\circledR}$ ), versão 20.0.

Para testar a hipótese da presente pesquisa, de que existe correlação positiva entre a satisfação e o comprometimento afetivo no trabalho dos docentes do curso de Ciências Contábeis, inicialmente, foi feito o teste de normalidade Kolmogorov-Smirnov, cujo objetivo é verificar qual o teste mais adequado a prosseguir, paramétrico ou não paramétrico. Com exceção da autonomia, às outras variáveis não são normais, assim, tendo sido rejeitada a hipótese de que os dados são normais, os testes utilizados foram os não paramétricos. Assim, para análise do objetivo geral deste estudo, foi realizada uma análise de correlação, cujo objetivo é determinar a força da relação entre duas observações (STEVENSON, 1981).

Em seguida, com o intuito de comparar o grau de satisfação e o nível de comprometimento afetivo entre as universidades procedeu-se, primeiramente, com o teste de normalidade, que revelou que os dados não são normais, e, posteriormente, efetuou-se o teste de Mann Whitney, cujo objetivo é testar duas amostras independentes (STEVENSON, 1981). E, por fim, para identificar o fator determinante da satisfação, foram verificadas as médias das variáveis relacionadas à satisfação através do software Microsoft Excel.

\section{ANÁLISE DOS RESULTADOS}

Observa-se que, 71,4\% dos docentes respondentes são professores da UNIFOR, enquanto que $28,6 \%$ são da UFC. Quanto ao nível de escolaridade, $64,3 \%$ dos docentes possuem o título de mestre, em contrapartida o número de doutores representa $19 \%$, percentual próximo ao de especialistas respondentes. A carga horária correspondente a maior parte dos docentes é 20 horas semanais (35,7\%). Além disso, a maioria está a mais de 7 anos $(66,7 \%)$ trabalhando na mesma instituição. Por fim, 54,8\% dos respondentes são do gênero masculino, o que não denota uma dispersão expressiva entre mulheres e homens. De forma geral, a amostra está caracterizada na Tabela 1. 
Tabela 1 - Caracterização da amostra

\begin{tabular}{|c|c|c|}
\hline Questões & Quantidade de respostas & $(\%)$ \\
\hline \multicolumn{3}{|c|}{ INSTITUIÇÃO } \\
\hline UNIFOR & 30 & $71,40 \%$ \\
\hline UFC & 12 & $28,60 \%$ \\
\hline Total & 42 & $100 \%$ \\
\hline \multicolumn{3}{|c|}{ NÍVEL DE ESCOLARIDADE } \\
\hline Graduação & 0 & $0,00 \%$ \\
\hline Especialização & 7 & $16,70 \%$ \\
\hline Mestrado & 27 & $64,30 \%$ \\
\hline Doutorado & 8 & $19,00 \%$ \\
\hline Total & 42 & $100 \%$ \\
\hline \multicolumn{3}{|c|}{ CARGA HORÁRIA } \\
\hline 20 horas & 15 & $35,70 \%$ \\
\hline 40 horas & 10 & $23,80 \%$ \\
\hline Dedicação Exclusiva & 9 & $21,40 \%$ \\
\hline Outro (especificar) & 8 & $19,00 \%$ \\
\hline Total & 42 & $100 \%$ \\
\hline \multicolumn{3}{|c|}{ TEMPO DE SERVIÇO NA IES } \\
\hline$<$ de 1 ano & 1 & $2,40 \%$ \\
\hline 1 a 4 anos & 10 & $23,80 \%$ \\
\hline 4 a 7 anos & 3 & $7,10 \%$ \\
\hline A partir de 7 anos & 28 & $66,70 \%$ \\
\hline Total & 42 & $100 \%$ \\
\hline
\end{tabular}

Fonte: Dados da pesquisa (2012).

Analisando os dados da Tabela 2 é possível constatar que existe correlação entre o grau de satisfação no trabalho e o nível de comprometimento afetivo que os docentes têm com o trabalho, visto que, o nível de significância calculado é menor que 5\%. Além disso, a relação existente é diretamente proporcional, pois o coeficiente de correlação é positivo. Quanto à força do coeficiente de correlação, observou que é moderada, já que ficou entre 0,31 e 0,59 (APPOLINÁRIO, 2006). Visto que o comprometimento afetivo é um dos tipos de comprometimento, conforme a teoria de Allen e Meyer (1990), esses resultados corroboram as pesquisas que apontam existir níveis de correlação positiva entre a satisfação e o comprometimento afetivo (COSTA; BASTOS, 2009; TRALDI; DEMO, 2012; PATRICK; SONIA, 2012; SRIVASTAVA, 2013).

Verificando individualmente as variáveis utilizadas para calcular o grau a satisfação dos docentes no trabalho, em relação ao nível de comprometimento afetivo, comprova-se o seguinte: as variáveis "trabalho", "relacionamento" e "perspectiva" possuem uma correlação positiva e moderada; e, em contrapartida, "salário" e "autonomia" não apresentam correlação. Nesse sentido, sob a perspectiva da teoria dos dois fatores de Herzberg (2003), as variáveis "salário" e "autonomia" não estão relacionadas ao comprometimento afetivo, pois, na verdade, são consideradas fatores higiênicos e, portanto, estabelecem ligação com a insatisfação. O estudo de Patrick e Sonia (2012), que analisou 300 funcionários de TI, em uma empresa da Índia, revelou que os componentes da satisfação que mais se relacionam com o comprometimento afetivo são "salários", "benefícios", "tratamento justo", "oportunidade para avanço" e "supervisão".

Da mesma maneira, é possível compreender porque as variáveis "trabalho" e "perspectiva" são correlacionadas ao comprometimento, pois, nesse aspecto, são consideradas fatores vinculados à satisfação, ou seja, são fatores motivacionais. Já em relação à variável "relaciona- 
mento", a teoria aponta que esta liga-se aos fatores higiênicos, mas o resultado desta pesquisa revela que a mesma está relacionada à satisfação, assim, pode-se entender que há um bom relacionamento entre os docentes e que isso é um fator que traz satisfação (HERZBERG, 2003).

Tabela 2: Relação entre o grau de satisfação e o nível de comprometimento no trabalho

\begin{tabular}{|c|c|c|c|}
\hline & Coeficiente de correlação & Sig & N \\
\hline Comprometimento & 1 &. & 42 \\
\hline Variável Trabalho &, $328^{*}$ & $\mathbf{0 , 0 3 4}$ & 42 \\
\hline Variável Relacionamento &, $333^{*}$ & $\mathbf{0 , 0 3 1}$ & 42 \\
\hline Variável Salário & 0,185 & 0,241 & 42 \\
\hline Variável Perspectiva &, $499^{* *}$ & $\mathbf{0 , 0 0 1}$ & 42 \\
\hline Variável Autonomia & 0,129 & 0,415 & 42 \\
\hline Satisfação com o trabalho &, $437^{* *}$ & $\mathbf{0 , 0 0 4}$ & 42 \\
\hline
\end{tabular}

*. Correlação significante a nível de $5 \%$.

**. Correlação significante a nível de $1 \%$.

Fonte: Dados da pesquisa (2012).

O resultado da comparação entre o grau de satisfação no trabalho e o nível de comprometimentos organizacional afetivo, dos docentes da UNIFOR e da UFC, leva a crer que não há diferença estatisticamente significante entre as os aspectos observados nas IES, porque o nível de significância de todos foi superior a 5\% (vide Tabela 3). Apesar de estarem em contextos de trabalho diferentes, IES privada (UNIFOR) e pública (UFC), onde cada um desses contextos tem características específicas, que fragilizam o comprometimento organizacional (ROWE; BASTOS; PINHO, 2011), os docentes não apresentam diferenças quanto à satisfação e ao comprometimento organizacional afetivo.

Tabela 3: Comparação entre satisfação e comprometimento das duas universidades ${ }^{a}$

\begin{tabular}{|c|c|c|c|c|c|c|c|}
\hline & $\begin{array}{c}\text { Variável } \\
\text { Trabalho }\end{array}$ & $\begin{array}{c}\text { Variável } \\
\text { Relaciona- } \\
\text { mento }\end{array}$ & $\begin{array}{c}\text { Variável } \\
\text { Salário }\end{array}$ & $\begin{array}{c}\text { Variável } \\
\text { Perspec- } \\
\text { tiva }\end{array}$ & $\begin{array}{c}\text { Variável } \\
\text { Autonomia }\end{array}$ & $\begin{array}{c}\text { Satisfação } \\
\text { com o tra- } \\
\text { balho }\end{array}$ & $\begin{array}{c}\text { Compro- } \\
\text { me-timen- } \\
\text { to }\end{array}$ \\
\hline $\begin{array}{c}\text { Mann } \\
\text {-Whitney } \\
\text { U }\end{array}$ & 149 & 143,5 & 147,5 & 176 & 156 & 153 & 153,5 \\
\hline $\begin{array}{c}\text { Wilcoxon } \\
\text { W }\end{array}$ & 614 & 221,5 & 225,5 & 641 & 234 & 231 & 618,5 \\
\hline Z & $-0,871$ & $-1,026$ & $-0,914$ & $-0,113$ & $-0,703$ & $-0,752$ & $-0,74$ \\
\hline $\begin{array}{c}\text { Asymp. } \\
\text { Sig. (2-tai- } \\
\text { led) }\end{array}$ & 0,384 & 0,305 & 0,361 & 0,91 & 0,482 & 0,452 & 0,459 \\
\hline $\begin{array}{c}\text { Exact Sig. } \\
\text { 2*(1-tai- } \\
\text { led Sig.)] }\end{array}$ &, $401 \mathrm{~b}$ &, $314 \mathrm{~b}$ &, $371 \mathrm{~b}$ &, $923 \mathrm{~b}$ &, $518 \mathrm{~b}$ &, $466 \mathrm{~b}$ &, $466 \mathrm{~b}$ \\
\hline
\end{tabular}

a. Variável de agrupamento: UNIVERSIDADES

b. Não corrigido para laços.

Fonte: Dados da pesquisa (2012).

Por fim, a análise do fator determinante, para a satisfação no trabalho, foi feita pela média dos fatores, que permitiu identificar que o "trabalho/conhecimentos e habilidades", bem como o "relacionamento com os colegas" se destacaram, pois possuem a maior média, conforme evidenciado na Tabela 4. 0 primeiro fator significa que o docente está satisfeito quanto à relação entre o trabalho 
que ele executa e seus conhecimentos e habilidades, trata-se de uma auto-avaliação. Já o segundo fator denota que os professores universitários, do curso de Ciências Contábeis, estão satisfeitos com o relacionamento com os colegas, o que reforça a análise feita a partir da Tabela 2 . O resultado não contraria a teoria dos dois fatores visto que a ausência dos fatores higiênicos produzirá insatisfação, mas a presença por si não dá garantias à satisfação, ou seja, há outros fatores que não foram investigados nesta pesquisa que fazem os docentes se sentirem satisfeitos em virtude das relações interpessoais.

Tabela 4 - Fatores determinantes da satisfação no trabalho

\begin{tabular}{|c|c|c|c|c|}
\hline Variável & Fatores & Média & Desvio padrão & $\begin{array}{l}\text { Coeficiente de va- } \\
\text { riação (\%) }\end{array}$ \\
\hline Trabalho & $\begin{array}{l}\text { Trabalho/ Habili- } \\
\text { dades e Conheci- } \\
\text { mentos }\end{array}$ & 4,43 & 0,630 & 14,23 \\
\hline Relacionamento & $\begin{array}{c}\text { Relacionamento } \\
\text { com Colegas }\end{array}$ & 4,43 & 0,770 & 17,39 \\
\hline Trabalho & $\begin{array}{c}\text { Trabalho Interes- } \\
\text { sante }\end{array}$ & 4,40 & 0,627 & 14,23 \\
\hline Relacionamento & $\begin{array}{l}\text { Relacionamento } \\
\text { com Superiores }\end{array}$ & 4,31 & 0,841 & 19,51 \\
\hline Autonomia & $\begin{array}{c}\text { Responsabilidade } \mathrm{x} \\
\text { Autonomia }\end{array}$ & 4,31 & 0,715 & 16,59 \\
\hline Trabalho & Carga horária & 4,27 & 0,742 & 17,38 \\
\hline Autonomia & $\begin{array}{l}\text { Liberdade de De- } \\
\text { cisão }\end{array}$ & 4,24 & 0,759 & 17,91 \\
\hline Trabalho & Tarefa x Função & 4,22 & 0,866 & 20,51 \\
\hline Perspectiva & $\begin{array}{c}\text { Desenvolvimento } \\
\text { Pessoal }\end{array}$ & 4,15 & 0,882 & 21,27 \\
\hline Perspectiva & Desempenho & 4,10 & 0,768 & 18,74 \\
\hline Autonomia & Supervisão & 4,10 & 0,983 & 24,00 \\
\hline Perspectiva & $\begin{array}{l}\text { Desenvolvimento } \\
\text { Profissional }\end{array}$ & 4,07 & 0,755 & 18,54 \\
\hline Trabalho & Reconhecimento & 3,95 & 0,986 & 24,96 \\
\hline Relacionamento & $\begin{array}{l}\text { Interesse da Uni- } \\
\text { versidade em Rela- } \\
\text { cionamento }\end{array}$ & 3,80 & 1,167 & 30,67 \\
\hline Perspectiva & Apoio ao Estudo & 3,56 & 1,097 & 30,81 \\
\hline Relacionamento & $\begin{array}{l}\text { Investimento da } \\
\text { Universidade em } \\
\text { Relacionamento }\end{array}$ & 3,51 & 1,098 & 31,26 \\
\hline Perspectiva & Promoção & 3,49 & 1,028 & 29,47 \\
\hline Salário & $\begin{array}{c}\text { Comparação com } \\
\text { Outras Universi- } \\
\text { dades }\end{array}$ & 3,31 & 1,137 & 34,36 \\
\hline Salário & $\begin{array}{c}\text { Salário Compatível } \\
\text { com Atividades }\end{array}$ & 2,93 & 1,257 & 42,92 \\
\hline Salário & $\begin{array}{l}\text { Condizente com a } \\
\text { Situação Financeira } \\
\text { da Universidade }\end{array}$ & 2,93 & 1,295 & 44,22 \\
\hline
\end{tabular}

Fonte: Dados da pesquisa (2012).

O fator "trabalho interessante" se destaca em segundo lugar como determinante para a satisfação e isso reforça a ideia de que os docentes estão na instituição porque gostam de dar aula conforme foi revelado na pesquisa realizada por Bouzada, Kilimnik e Oliveira (2012). Além disso, é 
possível observar que os três fatores da variável "salário" são os que possuem as médias menores de grau de satisfação, permitindo concluir que o salário é determinante para a insatisfação dos docentes, assim como nos achados por Silva Júnior (2001), que analisou se os 69 funcionários de hotéis de João Pessoa estavam satisfeitos com o trabalho, tendo como base a Teoria dos Dois Fatores de Herzberg, contudo contrariando os achados de Patrick e Sonia (2012). Tal constatação promove uma discussão sobre a necessidade das empresas de se esforçarem para desenvolver políticas alinhadas aos anseios de seus funcionários, entre elas estão: as práticas de gestão de pessoas, que estimulem o comprometimento dos funcionários com os objetivos da entidade.

\section{CONSIDERAÇÕES FINAIS}

O estudo objetivou, primeiramente, analisar a relação entre o grau de satisfação e o nível de comprometimento afetivo no trabalho, dos docentes universitários do curso de Ciências Contábeis de duas universidades cearenses. Além de comparar o grau de satisfação no trabalho e o nível de comprometimento afetivo com o trabalho dos docentes das universidades escolhidas; e identificar os fatores determinantes da satisfação no trabalho dos docentes. Para tais propósitos, foi realizada uma pesquisa descritiva, cujo método de pesquisa foi o survey. A coleta dos dados ocorreu através de questionário, onde se obteve 42 questionários respondidos.

$\mathrm{Na}$ análise dos dados, constatou-se que a maioria dos respondentes são homens, que trabalham na UNIFOR, estão na IES há mais de 7 anos e sua carga horária é de 20 horas/semanais. Em relação ao objetivo principal desta pesquisa, foi possível constatar que existe uma correlação positiva e moderada entre satisfação e comprometimento afetivo. Entretanto, não são todas as variáveis analisadas que apresentam correlação positiva, ou seja, diretamente proporcional. Constatou-se, assim, que as variáveis salário e autonomia não estão relacionadas ao grau de satisfação dos docentes.

Quando o grau de satisfação e o nível de comprometimento afetivo foram comparados entre as universidades estudadas, verificou-se que, apesar das diferenças do contexto no qual estão inseridas, sendo uma pública e a outra privada, não há diferença estatística, então, pode-se afirmar que as médias são estatisticamente iguais. $O$ trabalho/conhecimentos e habilidades e o relacionamento com os colegas são os fatores determinantes da satisfação dos docentes universitários. E os três fatores relacionados ao salário apresentaram médias entre 2,93 e 3,31, de forma que é clara a insatisfação dos professores com os seus salários, fator que é considerado higiênico.

Dessa forma, a hipótese dessa pesquisa foi aceita e a análise da teoria dos dois fatores pôde ser verificada e, de algum modo, ser revalidada. Contudo não é possível generalizar os resultados, pois apesar do cenário contemplar tanto instituição pública como privada, professores universitários de outras áreas não compuseram a população do estudo. Deste modo, ressalta-se que a utilização de apenas duas Instituições de Ensino Superior, o reduzido número de docentes participantes da amostra e a restrição aos profissionais do curso de Ciências Contábeis são as limitações dessa pesquisa. Sugere-se, portanto, para futuras pesquisas ampliar a população a ser investigada ao incluir outras IES e professores de outros cursos. Recomenda-se ainda a realização de entrevistas para complementar a análise dos dados, para identificar as características pessoais e as experiências de trabalho dos docentes, que permitam compreender com mais detalhes o comprometimento organizacional afetivo. 


\section{REFERÊNCIAS}

ALLEN, N.J.; MEYER, J.P. The measurement and antecedents of affective, continuance and normative commitment to the organization. Journal of Occupational Psychology, v. 63, p. 1-18, 1990.

AMBROSE, M. L.; KULIK, C. T. Old friends, new faces: motivational research in the 1990s. Journal of Management, v. 25, n. 3, p. 231-292, 1999.

APPOLINÁRIO, F. Metodologia da ciência: filosofia e prática da pesquisa. São Paulo: Thomson, 2006.

BABBIE, E. Métodos de pesquisa de survey. Tradução de Guilherme Cezarino. Belo Horizonte: UFMG, 2005.

BASTOS, A.V.B.;SIQUEIRA, M.M.M.;MEDEIROS, C. A. F.; MENEZES, I. G. Comprometimento organizacional. In: SIQUEIRA, M. M. M. (Org.) - Medidas do comportamento organizacional: ferramentas de diagnóstico e de gestão. Porto Alegre: Artmed, 2008. p. 49-95.

BORGES, E. F.; MEDEIROS, C. A. F. Comprometimento e ética profissional: um estudo de suas relações juntos aos contabilistas. Revista Contabilidade \& Finançanças, v. 18, n. 44, p. 60-71, maio/ago. 2007a.

BORGES, E. F.; MEDEIROS, C. A. F. Uma análise do grau de comprometimento dos profissionais em contabilidade. Revista Brasileira de Contabilidade - RBC, v. 36, n. 167, p. 51-63, set/out. 2007b.

BOUZADA, V. C. P. C.; KILIMNIK, Z. M.; OLIVEIRA, L. C. V. Professor iniciante: desafios e competências da carreira docente de nível superior e inserção no mercado de trabalho. Revista de Carreiras e Pessoas - ReCaPe, v. 2, n. 1, p. 1-18, jan./abr. 2012.

COLLIS, J.; HUSSEY, R. Pesquisa em administração: um guia prático para alunos de graduação e pós-graduação. 2. ed. Porto Alegre: Bookman, 2005.
COSTA, L. V. A relação entre a percepção de sucesso na carreira e o comprometimento organizacional: um estudo entre professores de universidades privadas selecionadas da grande São Paulo. 2011. 216p. Tese (Doutorado em Administração), Programa de Pós-Graduação em Administração, Universidade de São Paulo, São Paulo, 2011.

COSTA, F. M.; BASTOS, A. V. B. Múltiplos comprometimentos no trabalho: um estudo entre trabalhadores de organizações agrícolas do polo de fruticultura irrigada de Juazeiro/ Petrolina. Revista de Administração da UFSM, v. 2, n. 2, p. 280-297, 2009.

CRUZ, F. J. A.; CABRAL, A. C. A.; PESSOA,M N. M.; SANTOS, S. M.. Relações entre responsabilidade social interna e comprometimento organizacional: um estudo em empresas prestadoras de serviços. Revista Brasileira de Administração Científica, v. 3, n. 3, p. 163-182, 2012.

FARIAS, M. R. S. Desenvolvimento científico da contabilidade: uma análise baseada na epistemologia realista da ciência. 2012. 216p. Tese (Doutorado em Ciências Contábeis), Programa de Pós-Graduação em Controladoria e Contabilidade, Universidade de São Paulo, São Paulo, 2012.

GERON, C. M. S. Evolução das práticas contábeis no Brasil nos últimos 30 anos: da Lei 6.404/76 à Lei 11.638/07. 2008. 300p. Dissertação (Mestrado em Ciências Contábeis) - Faculdade de Economia, Administração e Contabilidade. Universidade de São Paulo, São Paulo, 2008.

GONDIM, S. M. G.; SILVA, N. Motivação no trabalho. In: ZANELLI, J. C., BORGES-ANDRADE, J. E.; BASTOS, A. V. B. (Orgs.) Psicologia, organizações e trabalho no Brasil. Porto Alegre: Artmed. 2004. p. 145-176.

GOULDNER, H. P. Dimensions of organizational commitment. Administrative Science Quarterly, v. 4, p. 468-490, 1960. 
HERZBERG, F. Mais uma vez: como motivar seus funcionários. In: VROOM, V. H. Gestão de pessoas, não de pessoal. Rio de Janeiro: Campus, 1999. p. 55-81.

HERZBERG, F. Uma vez mais: como motivar os funcionários. Harvard Business Review Brasil, v. 81, n. 1, p. 59-68, 2003.

LOCKE, E.A. The nature and causes of job satisfaction. In: DUNNETE, M.D. (ed.) Handbook of Industrial and Organizational Psychology. Chicago: Rand McNally College Publishing, 1976. p. 125-143.

MACIEL, C. O.; CAMARGO, C. Comprometimento, satisfação e cooperação no trabalho: evidências da primazia dos aspectos morais e das normas de reciprocidade sobre o comportamento. Revista de Administração Contemporânea, v. 15, n. 3, p. 433-453, 2011.

MAIA, L. G.; BASTOS, A. V. B. Comprometimento calculativo e retaliação: visão integrada dos conceitos em uma organização pública. Revista de Administração da UFSM, v. 4, n. 3, p. 390405, 2011.

MARTINEZ, M. C.; PARAGUAY, A. I. B. B. Satisfação e saúde no trabalho: aspectos conceituais e metodológicos. Cadernos de Psicologia Social do Trabalho, v. 6, p. 59-78, 2003.

MARTINS, G. A.; THEÓPHILO, C. R. Metodologia da investigação científica para ciências sociais aplicadas. São Paulo: Atlas, 2007.

MARTINS, M. C. F.; SANTOS, G. E. Adaptação e validação de construto da escala de satisfação no trabalho. PsicoUSF, v. 11, n. 2, p. 195-205, 2006.

MEDEIROS, C. A. F. Comprometimento organizacional: um estudo de suas relações com características organizacionais e desempenho nas empresas hoteleiras. 2003. 150p. Tese (Doutorado em Administração) - Faculdade de Economia, Administração e Contabilidade, Universidade de São Paulo, São Paulo, 2003.

MEDEIROS, C. A. F.; ALBUQUERQUE, L. G.; MARQUES, G. M.; SIQUEIRA, M.
Comprometimento organizacional: um estudo exploratório de seus múltiplos componentes. Revista Eletrônica de Administração - REAd, v. 11, n. 1, p. 1-16, 2005.

MEDEIROS, C. A. F.; ALBUQUERQUE, L. G.; SIQUEIRA, M.; MARQUES, G. M. Comprometimento organizacional: o estado da arte da pesquisa no Brasil. Revista de Administração Contemporânea., v. 7, n. 4, p. 187-209, jan/fev. 2003.

MENEGON, L. F.; CASADO, T. O contrato psicológico como ferramenta para a gestão de pessoas. Revista de Administração da USP - RAUSP, v. 41, n. 2, p. 125-135. São Paulo: FEAUSP, abr./jun. 2006.

MEYER, J. P.; ALLEN, N. J. A three-component conceptualization of organizational commitment. Human Resources Management Review. v. 1, p. 61-89, 1991.

MEYER, J. P.; STANLEY, D. J.; HERSCOVITCH, L.; TOPOLNYTSKY, L. Affective, continuance, and normative commitment to the organization: a meta-analysis of antecedents, correlates, and consequences. Journal of Vocational Behavior, v. 61, p. 20-52, 2002.

MOWDAY, R. T.; STEERS, R. M.; PORTER, L. W. The measurement of organizational commitment. Journal of Vocational Behavior, v. 14, p. 224-247, 1979.

PATRICK, H.; SONIA, J. Job Satisfaction and Affective Commitment. IUP Journal of Organizational Behavior, v. 11, n. 1, p. 23-36, 2012.

PELEIAS, I. R.; SILVA, G. P.; SEGRETI, J. B.; CHIOROTTO, A. R. Evolução do ensino da contabilidade no Brasil: uma análise histórica. Revista Contabilidade \& Finanças, Edição 30 anos de doutorado, v. 18, p. 19-32, jun., 2007.

PINTO, M. P. C. Comprometimento organizacional: um estudo de suas relações com desempenho na carreira. 2011. 144p. Dissertação (Mestrado em Administração), Programa de Pós-Graduação em Administração, 
Universidade Fundação Mineira de Educação e Cultura, Belo Horizonte, 2011.

PUGH, D. S.; HICKSON, D. J. Os teóricos das organizações. Rio de Janeiro: Qualitymark, 2004.

REGES, J. F. M. O nível de satisfação na previdência social. In: VANDERLEY, L. G. (Org.). Gestão de pessoas: facetas estratégicas. Fortaleza: Edições UFC: Imprensa Universitária. p. 117-132, 2012.

RIBEIRO, J. A.; BASTOS, A. V. B. Comprometimento e justiça organizacional: um estudo de suas relações com recompensas assimétricas. Psicologia: Ciência e Profissão, v. 30, n. 1, p. 4-21, 2010.

RIOS, A. L. F. As relações entre satisfação, longevidade no trabalho e comprometimento organizacional em uma empresa do segmento metalúrgico de Fortaleza. 2009. 137p. Dissertação (Mestrado em Administração e Controladoria), Programa de Pós-Graduação em Administração e Controladoria, Universidade Federal do Ceará, Fortaleza, 2009.

ROWE, D. E. O. Múltiplos comprometimentos e suas relações com o desempenho: um estudo entre docentes do ensino superior brasileiro em IES públicas e privadas. 2008. 242p. Tese (Doutorado em Administração), Escola de Administração, Universidade Federal da Bahia, Salvador, 2008.

ROWE, D. E. O.; BASTOS, A. V. B.; PINHO, A. P. $M$. Comprometimento e entrincheiramento na carreira: um estudo de suas influências no esforço instrucional do docente do ensino superior. Revista de Administração Contemporânea, v. 15, n. 6, p. 973-992, 2011.

SAMPIERI, R. H.; COLLADO, C. F.; LÚCIO, P. B. Metodologia de pesquisa. 3. ed., São Paulo: McGraw-Hill, 2006.

SCHERMERHORN, JR. J. R; HUNT, J.G; OSBORN, R.N. Fundamentos do comportamento organizacional. 2. ed. Trabalho de equipe e projeto de grupo. Bookman, Porto Alegre; 1999.

SILVA JÚNIOR, N. A. Satisfação no trabalho: um estudo entre os funcionários dos hotéis de João Pessoa. PsicoUSF, v. 6, n. 1, p. 47-57, jan./ jun. 2001.

SIQUEIRA, M. M. M.; GOMIDE JR., S. Vínculos do indivíduo com o trabalho e com a organização. In: ZANELLI, J. C., BORGESANDRADE, J. E.; BASTOS, A. V. B. (Orgs.). Psicologia, organizações e trabalho no Brasil. Porto Alegre: Artmed. 2004. p. 300-328.

SIQUEIRA, V. T. A.; KURCGANT, P. Satisfação no trabalho: indicador de qualidade no gerenciamento de recursos humanos em enfermagem. Revista da Escola de Enfermagem da USP, v. 46, n. 1, p. 151-157, 2012.

SOUZA FILHO, M.C. O reflexo da liderança, orientada pelos interesses dos liderados, no comprometimento organizacional: um estudo de caso da Gelita do Brasil. In: ENCONTRO DA ASSOCIAÇÃO NACIONAL DOS PROGRAMAS DE PÓS-GRADUAÇÃO EM ADMINISTRAÇÃO, 32, 2008, Anais... Rio de Janeiro: Anpad, 2008.

SRIVASTAVA, S. Job Satisfaction and Organizational Commitment Relationship: Effect of Personality Variables. Vision, v. 17, n. 2, p. 159-167, 2013.

STEVENSON, W. J. Estatística aplicada à administração. São Paulo: Harper \& Row do Brasil, 1981.

TRALDI, M.T. F.; DEMO, G. Comprometimento, bem-estar e satisfação dos professores de administração de uma universidade federal. Revista Eletrônica de Administração REAd, v. 18, n. 2, p. 290-316, 2012.

VARGAS, K. S.; BIRRER, J. A.; MINELLO, I. F. Estilos de aprendizagem e níveis de comprometimento organizacional: uma abordagem com residentes multiprofissionais da saúde. Revista de Administração da UFSM, v. 5, n. 3, p. 589-606, 2012. 